\title{
Intelligent investigations
}

\author{
P.E. Bryant
}

Theories of Development: Concepts and Applications, 2nd Edn. By William C. Crain. Prentice-Hall: 1985. Pp.306. Pbk \$20.95, £22.40.

Human Intelligence: Perspectives and Prospects.

By Robert Kail and James W. Pellegrino.

W.H. Freeman: 1985. Pp.224. Hbk \$19.95, £22.95; pbk \$12.95, £14.95.

Human Abilities: An Information-Processing Approach. Edited by R.J. Sternberg.

W.H. Freeman: 1985. Pp.259. Hbk \$19.95, £23.95; pbk \$13.95, £15.95.

PsyCHOLOGISTs began to construct tests of intelligence about 90 years ago, and from the start they had at least one certainty to help them choose the right material. They were sure that intelligence (whatever it is) grows during childhood, and therefore that any decent test would have to be more difficult for younger children to do than for older ones. So these pioneers set about finding tasks which tell younger and older children apart. An incidental consequence was that, as well as finding out how to measure intelligence, they launched the subject of developmental psychology. Both the initial uncertainty about the exact nature of intelligence and the certainty that it does at least develop in childhood are with us to this day, and they play a large role in each of these three books.

William Crain's is about the developmental side. It is the second edition of an extremely useful book which gives a clear account of many of the most important theories of intellectual and social development. The main distinction made is between theories which stress the possibility that internal forces control a child's development and those which argue for the overriding importance of the effects of experiences in the environment.

Crain spreads his net widely and some of his most interesting material is about theorists who usually do not figure much in books about developmental psychology. Thus he writes about Locke, Rousseau and also Montessori, and shows the important role their ideas had in the history of child psychology. The book has its limitations, however. It is about theories and has very little room for empirical evidence, which means that at times it is rather too uncritical. There is also one odd omission. Crain ignores the work of Vygotsky and of other Russian developmental psychologists, a particularly surprising gap because inclusion of the Russian contributions would have given the book a far better balance. As it is, most of the theories described are about the importance of internal forces in development; the Russians have more to say about environmental effects. Nevertheless Theories of Development is clear, enthusiastic and erudite, and it should help beginners and experts alike.

Though many of the ideas described by Crain are about the growth of intelligence in childhood, they do not tell us much about the psychology of adult intelligence. Theories about this vexed question have undergone a marked change during the past decade, as the book written by Robert Kail and James Pellegrino and the one edited by Robert Sternberg show. Until ten years ago, such theories tended to come in one or other of two distinct forms, either dealing with differences between people (based on the results of psychometric tests) or with the nature of intelligence in general. These two kinds of theory have had very different histories.

Those based on individual differences did not prosper. The tests were, and still are, a resounding practical success; but the theories which were derived from the results were all rooted in factor analysis, a statistical technique which allows one to make claims about the ingredients of intelligence ("intelligence consists of abilities a,b and c") but not about the way the system works. These static theories failed to convince many people and eventually went into a sharp well deserved decline.

It was virtually the opposite story with the theories about the mechanisms underlying apparently intelligent acts like remembering, learning, reasoning and problem solving. Such theories, which are commonly called information-processing theories, did not have much practical impact. But they did two things - one was to provide us with the viable account of the workings of intelligent behaviour, and the other was to produce a set of remarkably successful experimental paradigms.

The big change, which is charted by both Kail and Pellegrino and the contributors to Sternberg's book, arrived when these two separate traditions merged and people began to apply informationprocessing theories and the experimental paradigms that went with them to individual differences. The two books take much the same point of view and deal with much the same material when they describe this development. Both conclude that there is very good reason for using models of information processing to account for human intelligence.
How well do they make their case? The main way that both books set about doing so is to cite evidence for a strong relationship between a subject's performance in the experimental paradigms of information-processing and that in particular types of intelligence tests. To take two examples, skill at judging whether two words represent things in the same taxonomic category (a common information-processing task) is related to verbal intelligence scores, while success at working out whether two subjects presented in different rotational planes are identical objects or not (another information-processing task) is related to performance in spatial intelligence tests. Note the specificity of these connections.

There are, however, some gaps in the evidence. Many of the relationships reported in these two books are not nearly specific enough. For example Earl Hunt, one of the contributors to Sternberg's book, claims a strong relationship between performance in various verbal information-processing experiments and in verbal intelligence tests; but he fails to point out - and it is a very serious omission - that in many of the cases that he describes the relationship is much too broad. Nonetheless, the two books do manage to make a convincing case for using information-processing ideas in theories about human intelligence, and both of them do so in a clear and simple way which students will find extremely helpful.

Despite this brave, new impetus we cannot yet say exactly what human intelligence is. In fact the single certainty that we do have is the one with which the subject began - that intelligence increases during childhood. All three books make much of this plain fact. Kail and Pellegrino, and Crain, give good, clear accounts of the main theories of the development of intelligence. The developmental theme also looms large in Sternberg's book, most notably in a first-rate chapter by Campione, Brown and N. Bryant. Among other things, these authors describe some evidence of marked differences between younger and older children whose absolute scores (and therefore mental ages) are the same; the younger ones form rules and generalize from one problem to another much more efficiently. So the rate of intellectual development is also a crucial factor and that, I think, might well be linked to the development of information processing. There is still a lot to find out about human intelligence and its development but, as these three books show, we already have some interesting information to consider.

P.E. Bryant is Watts Professor in the Department of Experimental Psychology, University of Oxford, South Parks Road, Oxford OX1 3UD, UK. 